\title{
The role of the concept of corporate social responsibility in promoting goods and services in the economically developed countries
}

\author{
Marina $V$. Andriianova ${ }^{1}$ and Valeriia $V$. Kruchinina ${ }^{2}$ \\ ${ }^{1}$ Moscow State Institute of International Relations (MGIMO University), Pr. Vernadskogo, 76, \\ Moscow, Russian Federation \\ ${ }^{2}$ ISS - Intelligent Security Systems (ISS-Soft Ltd), Skolkovo innovation center, Bolshoy boulevard \\ 42, bld 1, 143026 Moscow, Russian Federation
}

\begin{abstract}
As companies lost their reputation amid ethical scandals, socioethical marketing as well as social responsibility concept, became vital components and a fundamental difference of successful companies. This shift towards socially responsible marketing is indicative of shifting the focus from production and goods/services to the consumer and his philosophy of life, as well as to social ethics. However, with the changing environment especially in digitization encompassing all spheres of society, companies also have to improve their marketing tools including marketing communications as a key factor in the formation of the socially oriented relationships between manufacturer and consumer.
\end{abstract}

\section{Introduction}

Conventionally, marketing communications are considered as the relationship formed by a firm with an external environment. As marketing tools can be also considered the product itself, its packaging and labeling; advertising and PR; trade marketing and direct marketing; branding; online promotion; loyalty campaigns; sponsorship and philanthropy; personal sales and after-sales service; various kinds of events (exhibitions, seminars, conferences). Ultimately, the purpose of all marketing communications is to convince the consumer (potential or actual) that the product or service provides the fullest possible satisfaction of its needs, which should give an impulse to acquire the proposed product or service.

In recent decades, major changes in the economy and society have taken place; these changes have a significant impact on all spheres of activity of any organization. They are also particularly important to ensure effective interaction with the target audience. Marketing communications are an organization's outpost in its relationship with the consumer. Often actual customer appeal of the goods forming the relationship to the producer and the product or service offered is less important than the values embedded in the concept of the social responsibility of the manufacturing company. The effectiveness of the organization's market strategy, its competitiveness, and, ultimately, its long-term viability is directly dependent on the understanding of changes in the external environment and the ability to create both the concept of social responsibility and communication with stakeholder groups. 


\section{Methods}

In classical economic theory, market availability is a systemic factor that determines the existence of an organization. [1] From the point of view of producers of goods and services, the markets of economically developed countries are the most attractive. The high standard of living peculiar to the economically developed countries, shows, on the one hand, a high level of capacity to pay and, on the other, a high level of consumption, which is becoming the norm and a social value. As a result, a sustained high level of demand for a wide range of goods and services is created (fig. 1).

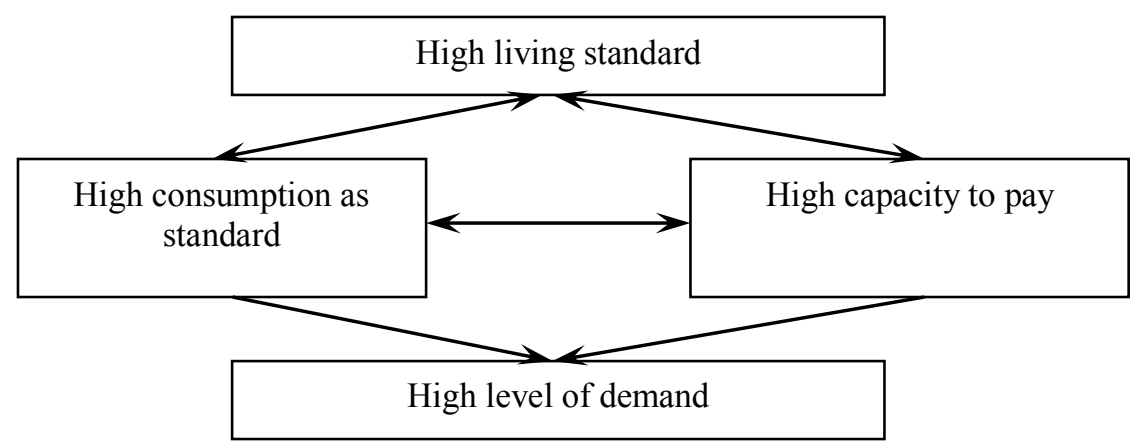

Fig. 1. The link between high living standards and high demand.

It is evident that a high standard of living is a multi-factor concept, it would be extremely narrow and one-sided to assess it only by the income level of the population. One suitable way of considering living standards is through an indicator such as the Human Development Index for which an entire set of indicators is taken into consideration.

Table 1. Top 20 countries by human development level. [2]

\begin{tabular}{|c|c|c|c|c|c|c|c|}
\hline 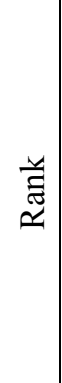 & $\begin{array}{l}\stackrel{\Xi}{\Xi} \\
\text { ठ }\end{array}$ & 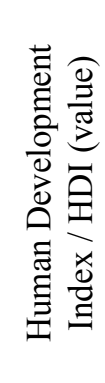 & 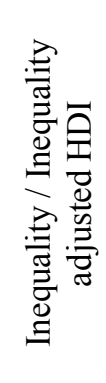 & 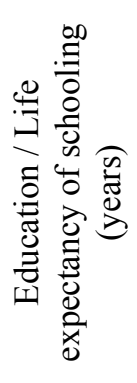 & 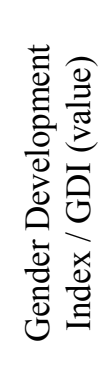 & 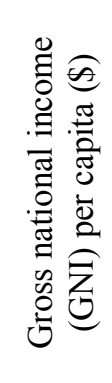 & 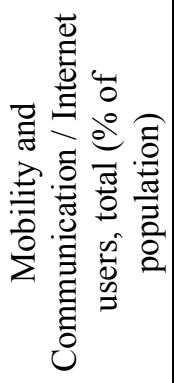 \\
\hline 1 & Norway & 0.954 & 0.889 & 18.1 & 0.990 & 68059 & 96.5 \\
\hline 2 & Switzerland & 0.946 & 0.881 & 16.2 & 0.963 & 59375 & 89.7 \\
\hline 3 & Ireland & 0.942 & 0.872 & 18.8 & 0.975 & 55660 & 84.5 \\
\hline 4 & Germany & 0.939 & 0.861 & 17.1 & 0.968 & 46946 & 89.7 \\
\hline 5 & Hong Kong & 0.939 & n.a. & 16.5 & n.a. & 60221 & n.a. \\
\hline 6 & Australia & 0.398 & 0.862 & 22.1 & 0.975 & 44097 & 86.5 \\
\hline 7 & Iceland & 0.938 & 0.885 & 19.2 & 0.966 & 47566 & 99.0 \\
\hline 8 & Sweden & 0.937 & 0.874 & 18.8 & 0.982 & 47955 & 92.1 \\
\hline 9 & Singapure & 0.935 & 0.810 & 16.3 & 0.988 & 83793 & 88.2 \\
\hline 10 & Netherlands & 0.933 & 0.870 & 18.0 & 0.967 & 50013 & 94.7 \\
\hline 11 & Denmark & 0.930 & 0.873 & 19.1 & 0.980 & 48836 & 97.6 \\
\hline 12 & Finland & 0.925 & 0.876 & 19.3 & 0.990 & 41779 & 88.9 \\
\hline
\end{tabular}


Continuation of Table 1. Top 20 countries by human development level.

\begin{tabular}{|c|l|c|c|c|c|c|c|}
\hline 13 & Canada & 0.922 & 0.841 & 16.1 & 0.989 & 43602 & 91.0 \\
\hline 14 & New Zeland & 0.921 & 0.836 & 18.8 & 0.963 & 35108 & 90.8 \\
\hline 15 & $\begin{array}{l}\text { United } \\
\text { Kingdom }\end{array}$ & 0.920 & 0.845 & 17.4 & 0.967 & 39507 & 94.9 \\
\hline 16 & United States & 0.920 & 0.797 & 16.3 & 0.991 & 56140 & 87.3 \\
\hline 17 & Belgium & 0.919 & 0.849 & 19.7 & 0.972 & 43821 & 88.7 \\
\hline 18 & Liechtenstein & 0.917 & n.a. & 14.7 & n.a. & 99732 & 98.1 \\
\hline 19 & Japan & 0.915 & 0.882 & 15.2 & 0.976 & 40799 & 84.6 \\
\hline 20 & Austria & 0.914 & 0.843 & 16.3 & 0.963 & 46231 & 87.7 \\
\hline
\end{tabular}

The data presented in the table clearly shows that, in addition to the high spending capacity in economically developed countries due to the income level of the population, the nature, and structure of demand is influenced by many other factors related to individual, group, and societal attitudes that are difficult to analyze, assess, forecast, and manage by economic entities. Adding the religious aspect of the population, it becomes apparent that the developed economies are currently experiencing a strong tendency for needs to be fragmented and demand at a combined high level to be tremendous detailed about the target audience. Account must be taken of the fact that in economically developed countries have historically been both the most stringent requirements for goods and services producers so as the tradition and practice of social responsibility of business. For this reason, businesses are expected to meet new social conditions, and will not limit itself by a purely applied production function. [3]

The structure and composition of the target audience are constantly changing; the target audience ceases to be stable with permanent characteristics. In such circumstances, the situational approach is particularly important, so the producer needs to know and understand the specifics of his target audience at any given time. [4]

In economically developed countries, most consumers have equal access to the same set of goods and services. [5] Personification is possible only through the formation of a unique combination for the individual. The stronger the consumer's desire for individuality, the more fragmented the needs, the wider the range of goods, and services available to meet them, the less likely the exact repetition of a consumer's personal choice, the higher the consciousness of one's personality. Thus, a vicious circle emerges, leading to the increasing fragmentation of needs. The phenomenon of identity through the pool of needs has led to new challenges for manufacturers of goods and services, and problems in social life. The wait-and-see attitude or a lie-up position in such a situation results to be costly; a paradoxical phenomenon in a modern society that aspires to humanistic values, tolerance, and multiculturalism is the phenomenon of cancel culture and rejection of cultural appropriation. Some examples are given below:

- Reputational scandals in both companies were linked to the statements of their directors, which were humbling in regards to people with excess weight. The Abercrombie\&Fitch refusal to manufacture and sell XL- and XXL- sized clothing instigated an active protest with the slogan "Fitch out Abercrombie (please)", which has seriously damaged the reputation of the company and significantly worsen its financial performance. The Victoria's Secret brand refused to cooperate with its director a few days after his interview, brought public interest. The plus-size collection was quickly developed and the first-ever Victoria's Secret plus-size model Ali Tate Cutler was invited.

- Flora vs Starbucks. In a Flora margarine campaign in South Africa, Unilever banked on conservative values and failed, because of not taking into consideration that the target audience has already undergone a significant transformation. The dudgeon caused by ambiguous advertising around the world forced the company to invest a lot of effort to 
settle the situation in order to keep the customers. Starbucks, by contrast, acquires additional customers through an effective information campaign so everyone knows that Starbucks, according to the chairman emeritus in Starbucks Howard Schultz, is trying to cover "all existing varieties". Howard Schultz said, "If you feel, respectfully, that you can get a higher return than the $38 \%$ you got last year, it's a free country. You can sell your shares in Starbucks and buy shares in another company".

Such examples demonstrate that the market rules for "the game" are irretrievably changing. Levitt's Total product concept (TPC) is a well-known concept that describes a product as a set of mandatory and additional attributes that influence consumer perception and choice. It should be admitted that those attributes that reflect the social position of the manufacturer in the economically developed countries are already firmly in the mandatory category. This fact is beyond all question; however, it is interesting to consider the causes and consequences of such transformation.

The peculiar must-have of a modern product or service is its value component. This may be compared, for example, with the existence of a pool of policy rules and prohibitions in religious systems, such as Islam or Judaism. This is a well-structured, strict system, understood and accepted by all members of the community. It is a system of rules that interferes with all spheres of life and all activities committed by a person. A person with certain religious beliefs cannot afford to commit or acquire something that contravenes the established pattern of behavior. Therefore, the modern consumer considers a product not simply a means of satisfying basic needs but as a carrier of values and beliefs. The purchase of a product or service is possible only if the value systems of the manufacturer and the consumer coincide; in the worst-case scenario, the value system of the producer should at least not contradict the system of consumer beliefs. Such consumer behavior is common to consumers in economically developed countries for various reasons but from an economic point of view, this is possible because of market saturation and lack of monopolists. [6] In fact, the consumer always has a choice - you can simply purchase a product or service with similar consumer properties of another manufacturer with a value system that is considered acceptable to the consumer. Manufacturers used to create new needs by addressing consumers like the characters of Sorokin's "Ice trilogy", who to awaken their sisters and brothers with sleeping hearts were beaten on their chest with an ice hammer and cried out, "Speak straight from your heart!" Now the insistent demand "Speak straight from your heart" is addressed already from consumers to manufacturers, and the ice hammer will go down on anyone who refuses to respond. It is no longer enough to offer a good product or service to the market; the producer is often obliged to justify the right of the good or service existing from the perspective of public interest.

\section{Results and subsequent discussion}

As a result, it is the value of a product or service that should represent an individual projection of the social and personal interest of the consumer. [7] In fact, the range of goods and services favored by the modern consumer forms his (consumer's) social avatar. This consumer avatar could tell people who are the consumers, what are their values and beliefs, and their role in society. The modern human tells the world what he is in the public sense through the goods and services he purchases. [8] Hence, the concept of social responsibility of the manufacturer is so important today. The brand in today's world is firmly and closely linked to those values and preferences underlying the concept of corporate social responsibility. This relationship has long been known, however, now it has acquired a qualitatively different content, the changes have affected both the concept of corporate social responsibility and marketing communications. 
Previously, the social concept of business was based on the principles of a responsible and conscientious approach to production and meeting the requirements of the target audience. Actually, this is not enough - the manufacturer should demonstrate his stance on the hottest social topics. Any deviation in this situation would be interpreted as unfavorable to the producer.

Marketing communications used to serve as a means to inform consumers about the manufacturer's values, it just was not so important - there were the consumer properties of goods and services in the first place. [9] The value-added information function has now become a priority for marketing communications. It should be noted that active digitization processes particularly affecting economically developed countries are further affecting marketing activities. First of all, it is necessary to be aware of such features of modern digital marketing communications as instant distribution of marketing materials on the Internet, the impossibility of their total elimination, and their accessibility to a wide range of users. It turns out that marketing materials made according to the specific characteristics of the target audience become available to multiple user groups for which they were not purposed before; however, the information diffusion process is extremely rapid, almost instantaneously, and if necessary, the materials cannot simply be withdrawn and may become a stain on the reputation of the company forever. This means that the importance of both the concept of corporate social responsibility and marketing communications is increasing in the modern world, but the corresponding risks are also increasing. [10]

By analogy to strategic management, modern companies should change their approach to social responsibility management, so a prescriptive approach should be abandoned and a diverse, flexible, adaptive system of social responsibility should be created. Ideally, this flexibility should come out through marketing communications in the form of special signals, which would prevent the situation when customers raise questions. For example, questions about the name of the Fazer chocolate "Geisha" and the presence of a drawing of a man in a fez on the packaging of the Valio Greek yogurt caught the manufacturers unawares, because they have never thought that such small details shall deserve attention, and it was not clear to consumers how manufacturers feel about such hot social topics as an objectification of women and discrimination on the basis of nationality and religion.

The variability of the social responsibility concept should not be revealed in evasiveness, indulgence, and hypocrisy in dealing with consumers; the manufacturer shall be ready to state his position on hot social topics. This approach should be implemented through a well-designed system of marketing communications that gain additional value as the most important link between the manufacturer and the consumer. New demands on the social responsibility concept create an additional load on marketing communications functionality. The varying nature of these functions should be mentioned. For example, signal/emergency function - in a peaceful atmosphere, marketing communications should fully transmit to the consumer the necessary weak signals about the manufacturer's value system, taking into account specific features of communication (such as the working language, the presence of slang, etc.); if the situation worsens, the marketing communication system should identify immediately the source and essence of the tension and transmit the necessary information to the manufacturer. The balancing/crisis management function - in a peaceful environment it means the function of adapting the manufacturer's concept of corporate social responsibility to the needs of all stakeholders (i.e. identification of attitudes, stakeholders' opinions, and identification of appropriate weak signals clarifying the concept of social responsibility); in a crisis situation, this function should ensure the immediate mobilization of the marketing communications system as well as to represent the company's position, which should at least not to impair its market position. The need for the qualitative implementation of these functions explains the increasing importance of the components of the marketing communication system that 
ensures direct and operational communication with the stakeholders, especially it is referred to the social media marketing and community management.

\section{Conclusions}

The analysis of development trends and the transformation of the interaction between the social responsibility concept and the company's marketing communications system testify that their role in shaping consumer image and consumer relations that have a direct impact on purchasing decisions has increased noticeably. This is linked to the general improvement of well-being and quality of life of the population in economically developed countries as well as to the processes directly related to the current market conditions (for example, to the digitization process). The manufacturers can no longer confine themselves to a declaration of commitment to the basic humanistic values; they should become full participants in contemporary social processes and state their position and attitude to the hottest social topics. Goods and services in economically developed countries are no longer a means to meet the immediate needs, so they have turned into the consumer's expression of his public position. Since the process of redesigning the concept of social responsibility and the marketing communications systems already been launched but in the initial stage, the technical implementation of these changes is not yet evident. Rather, at this point in time, there is a broad area of concern that requires appropriate solutions.

\section{References}

1. N. Capon, R. Capon, J. Hulbert, Managing Marketing in the 21st Century (2009)

2. Human Development Report Office (2019), hdr.undp.org

3. K. Jerath, M. Brown, How the marketing technology landscape will transform in the new year (2019), adweek.com

4. A. Aribag, T. Otter, D. Zantedeschi, G. Allenby, T. Bentley, D. Curry, M. Dotson, T. Henderson, E. Honka, R. Kohli, K. Jedidi, S. Seiler, X. S.Wang, Customer Needs and Solutions, 1, 82 (2018)

5. J. Kagan, Digital Marketing: Strategy \& Tactics (2018)

6. M.V. Andriianova, Innovations and investment, 11, 103 (2019)

7. K. Jerath, P. Fader, B. G. S. Hardie, European Journal of Operational Research, 1, 340 (2016)

8. D. Lerman, R.J. Morais, D. Luna, The Language of Branding: Theory, Strategies, and Tactics (2017)

9. K. Wilcox, J. Laran, S. Sen, Does Imitation Benefit the Imitated Brand? The Effects of Target Ambiguity and Processing Mindset on Judgment (2018)

10. V. Swaminathan, A. Sorescu, J. E.M. Steenkamp, T. Clayton, G. O'Guinn, Bernd Schmitt, Journal of Marketing, 2, 24 (2020) 